139 THE ROLE OF HEART RATE AND AFTERLOAD ON CARDIAC OUTPUT IN NEWBORN LAMBS. Robert E. Shaddy, Carlos Li, Michae1 Tyndal1, David F. Teitel, Abrahan M. Rudolph. Cardiovascular Research Institute and Dept. of Pediatrics, Univ. California, San Francisco.

Previous studies have suggested that increases in heart rate (HR) may represent the primary mechanism available to the newborn for increasing cardiac output ( $\mathrm{CO}$ ). In this study, we examined the independent effects of $\mathrm{HR}$ and afterload changes on $\mathrm{CO}$ in newborn lambs. Atrioventricular node ablation was performed in eight newborn lambs (3-10 days of age) by formalin injection, and the right ventricle was paced at a HR of 200 (baseline). Nine studies were performed in young lambs (less than 12 days of age), and nine studies in older lambs (greater than 12 days of age). $\mathrm{Co} / \mathrm{kg}$ increased progressively with increasing $\mathrm{HR}$. The maximum $\mathrm{co} / \mathrm{kg}$ attained was similar for both groups, but this was achieved at a higher HR in the younger lambs. From a baseline HR of 200 , the maximum increase in $\mathrm{Co} / \mathrm{kg}$ attained by increasing HR was $6.7 \%$ in the younger lambs, and $8.9 \%$ in the older lambs. At lower HR's $(70 / \mathrm{min})$, oxygen consumption (V02) decreased, and systemic vascular resistance (SVR) increased. With a fixed HR of 200 , nitroprusside caused an increase in $\mathrm{CO} / \mathrm{kg}$ of $10.5 \%$ in the younger lambs, and $11.8 \%$ in the older lambs. Phenylephrine caused a decrease in $\mathrm{CO} / \mathrm{kg}$ of $19.3 \%$ in the younger lambs, and $10.6 \%$ in the older lambs. HR above baseline has limited value in increasing CO in newborn lambs. At lower HR's, CO and VO2 fall, and SVR increases. Decreasing afterload produces modest increases in $\mathrm{CO}$. Increasing afterload results in decreases in $\mathrm{CO}$, and these changes were most striking in the younger lambs.

MATERNAL DIABETIC CONTROL AND HYPERTROPHIC CARDIOMYO-

140 PATHY (HYC)IN INFANTS OF DIABETIC MOTHERS(IDM). PaUline Sheehan, Thomas RowIand, Bhavesh Shah, Vincent McGravey Edward Reiter. Dept. of Peds, Baystate Med.Ctr., springfield,MA.

Transient HyC occurs frequently in IDM. This may result from fetal hyperinsulinemia secondary to maternal hyperglycemia in the $3 r d$ trimester. Prospective study was designed to determine the incidence of IDM HyC and to investigate its relationship to 3 rd trimester maternal diabetic control, measured by $\mathrm{HbA} .20$ insulin dependent diabetic women and their infants and 30 normal babies (controls) were enrolled in the study.Maternal HbA, was obtained at the time of delivery and $M$-mode echocardiography was performed on all infants at 24-72 hrs.age. Cord blood glucose, follow-up glucose at $q 30 \mathrm{~min} \times 4$ and chest $x$-ray were obtained in all IDM. Diagnosis of HyC was based on ratio of absolute ventricular septal thickness related to body weight $(S / B N-m m / k g)$.

\begin{tabular}{|c|c|c|}
\hline & $\operatorname{IDM}(n=20)$ & Control $(n=30)$ \\
\hline Mean $G A$ wks (range) & $38.0(36-40)$ & $40.2(38-42)$ \\
\hline Mean BW $\mathrm{kg}$ (range) & $3.8 \quad(2.7-4.7)$ & $3.5(2.6-4.4)$ \\
\hline$\% L G A$ (>90 percentile) & 60 & 30 \\
\hline Mean Serum $H b A_{7} \%$ (range) & $7.6(5.7-9.4)$ & $(4.8-7.7)$ \\
\hline Abs.Vent.Sept. Thick/BW & $1.19 \pm 0.29$ & $0.96 \pm 0.17$ \\
\hline
\end{tabular}

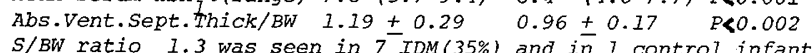
(3\%), Chi square=8.95, $P<.01$. None of these subjects had clinical evidence of congestive heart failure.

No correlation existed between maternal $\mathrm{HbA}$ at term and incidence of neonatal HyC, macrosomia and hypoglycemia. These data do not support 3rd trimester hyperglycemia with consequent fetal hyperinsulinemia as a trigger mechanism for HyC.

\section{PCHOCARDTOGRAPHIC PREDICTORS OF} PULMONARY HYPERTENSION IN CONGENITAL HEART DISEASE E.B.SIDERIS,M.D., SOULA MESSINIS SIDERIS, R.N. J.E. JONES,M.D., AMARILLO, TEXAS Critical review of Echocardiographic (Echo) predictors of pulmonary artery pressure(PA), was attempted in 37 cases who had Echos within 10 days from cardiac catheterization. Preejection period to ejection time(RVPEP/ET), time to peak velocity corrected for RVET(TPV/RVET) and negative presystolic velocity (a wave) were used. All studies were done in Infants and children with 4-chamber hearts, normally related great vessels and various defects. All 3 indices correlated poorly with PA in the mixed group. The presence of the "a wave" could separate patients with PA systolic less than $30 \mathrm{mmHg}$ in $30 / 37$ cases. " "a wave" indistinguishable in 4 cases, 3 false estimates)

RVTPV/ET less than .35 could separate patients with PA systolic over $30 \mathrm{mmHg}$ if cases with a pulmonic gradient more than $20 \mathrm{mmHg}$ were excluded and RV outflow measurements were used in patients with patent ductus arteriosus (Technical estimation Impossible in 5 cases). RVPEP/ET more than .35 could separate cases with PA systolic over $30 \mathrm{mmHg}$. (Technical estimation impossible in 5 cases, 6 false estimates).

We conclude that there are both technical problems and IImitations in the application of all used indices for the non invasive prediction of pulmonary hypertension in congenital heart disease.

Invasive estimation of PA pressure is imperative in cases under question.
142 ELECTROPHYSIOLOGIC EVALUATION OF TETRALOGY OF FALLOT 142 (TOF) REPAIR: EARLY POSTOPERATIVE STUDIES Robert Boxer Sharanjeet Singh, M. Andre Vasu, Vincent Parne11, North Shore Cardiac arrhythmias are common after repair of TOF and are associated with sudden death. We performed 9 electrophysiologic studies in 5 patients (pt.), ages 6-16 yrs. With ToF $1-26$ days after repair to identify pt. at risk for arrhythmias. Rapid atrial pacing and programmed atrial and ventricular stimulation were carried out using intracardiac catheters ( 2 pt. -2 studies) or epicardial pacing wires placed intraoperatively on the right atrium, right ventricular apex (RVA) and outflow tract (RVOT, 5 pt. -7 studies). Epicardial pacing studies were performed at the bedside or in the intensive care unit (ICU). Junctional rhythm was present at the first study in $2 \mathrm{pt}$. Wenckenbach periodicity
wastional renthm occurred at an average cycle length of $236+88$ Msec. Dual pathway atrio-ventricular conduction, anterograde and retrograde, was observed in $1 \mathrm{pt}$. Atrial flutter was induced in $1 \mathrm{pt}$. Ventricular effective (VERP) and functional (VFRP) refractory periods (RP) determined at the RVA (VERP $193.8 \pm 19.3$, VFRP $212.5+$ $19.8 \mathrm{mesc}$ ) and RVOT (VERP $197.5 \pm 19.2$, VFRP $215.3 \pm 19.3 \mathrm{msec}$ ) were similar. The ventricular RP determined by intracardiac or responses were observed in $1 \mathrm{pt}$. Single $\left(\mathrm{S}_{1}, \mathrm{~S}_{2}\right)$ or double $\left(\mathrm{S}_{1}\right.$,

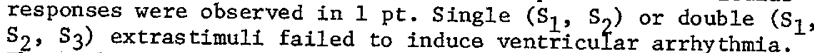
These observations suggest that electrophyslologic studies can be safely carried out in the immediate post operative period at the bedside or in the ICU and may be helpful in identifying pt. at risk of developing cardiac arrhythmia.

14 MYOCARDIAL METABOLIC AND HEMODYNAMIC CHANGES 43 DURING ACUTELY INDUCED ASPHYXIA IN FETAL LAMBS. R. Kendrick Slate, Anthony M. Mills, and Abraham M. Rudolph. $\frac{\text { Cardiovascular Research Institute and Dept. of }}{4}$ Pediatrics, Univ. California, San Francisco.

Two days after instrumentation, we measured heart rate (HR), arterial blood pressure (BP), left ventricular myocardial blood flow (MBF), and myocardial consumption of oxygen, glucose and lactate in 6 fetal sheep (118-128 days gestation) in utero during acute progressive asphyxia induced by gradual constriction of a common uterine artery snare. Ascending aortic blood oxygen content decreased by $70 \%$ from 7.5 to 2.2 $\mathrm{m} 1 / \mathrm{dl}$. Ascending aortic blood oxygen saturation fell from $60 \%$ to $15 \%$. $\mathrm{pH}$ fell from 7.40 to 7.04 , while $\mathrm{PCO}_{2}$ increased from 46 to 72 torr. Coronary sinus $\mathrm{PO}_{2}$ fell from 11.6 to 6.6 torr. MBF increased $317 \%$ above the control of 239 $\mathrm{m} 1 / 100 \mathrm{~g} / \mathrm{min}$. Hemoglobin concentration was maintained from 9.3 to $10.8 \mathrm{~g} / \mathrm{d} 1$ during the study. $\mathrm{HR}, \mathrm{BP}$, and rate-pressure product remained unchanged. Myocardial oxygen consumption and extraction were maintained until an arterlal oxygen saturation of $20-25 \%$, after which they decreased. During hypoxemia, myocardial glucose consumption markediy increased and net lactate uptake by the myocardium occurred until an arterial $\mathrm{PO}_{2}$ of 12 torr $\left(\mathrm{O}_{2}\right.$ saturation of $21 \%$ ) was reached. Below this level lactate production occurred in 3 of 6 fetuses. Thus the fetal lamb has a marked reserve to increase myocardial blood flow and maintain myocardial oxygenation and substrate delivery during acute severe asphyxia.

SERMM ARGININE VASOPRESSIN RESPONSES IN CONGENITAL HEART DISEASE

144 Julian M. Stewart, Guillermo Zeballos, Paul K. Woolf, Harry S. Departments of Pediatrics and Physiology,

In addition to its antidiuretic properties, arginine vasopressin (AVP) is a potent vasoactive homone. If unopposed by baroreceptor mediated reflexes, even low serum levels of AVP may exert pressor effects. Since early life is associated with an enhanced ability to release AVP and with an increase in its candiovascular effects, we evaluated whether congestive heart failure (CHF) is a stimulus for AVP release. AVP levels were measured by RIA using the modified Bentonite technique in 40 infants and children divided into 5 groups: Group I $(n=7)$ with CHF; Group II $(n=6)$ with cyanotic heart disease; Group III $(n=3)$ with persistent neonatal pulmonary hypertension; Group IV $(n=12)$ stressed infants with respiratory disease but no heart disease; and Group $\vee(n=12)$ healthy instressed controls. Group IV had statistically higher AVP levels healthy unstressed controls. Group IV had statistically higher AVP levels
$(13 \mathrm{pcg} / \mathrm{ml} \pm 6)$ when compared to Group $V$ nomals $(6 \mathrm{pcg} / \mathrm{ml} \pm 2)(\mathrm{p}<0.05)$. $(13 \mathrm{pcg} / \mathrm{ml} \pm 6)$ when oompared to Group $V$ normals $(6 \mathrm{pcg} / \mathrm{ml} \pm 2)(\mathrm{p}<0.05)$.
Groups II \& III were not significantly different from Group $V(7 \mathrm{pcg} / \mathrm{ml} \pm 5$ and $6 \mathrm{pcg} / \mathrm{ml} \pm 2$ respectively). CHF patients (Group I) had variable AVP levels witt peak levels markedly elevated above other groups (102 $\mathrm{pcg} / \mathrm{ml} \pm 135),(p<0.05)$; and further increased with worsening clinical status.

Additional data suggest that hyperosmotic angiographic contrast media increase AVP levels by 2 to 10 times pre-dye levels in most instances $(n=12$ of 15 patients, $p<0.02$ ).

We conclude that AVP levels are increased in children with CHF and that diagnostic interventions such as angiography may further elevate AVP. This may result in increased cardiac afterload further impairing already diminished
cardiac function. 